\title{
Two Pharmacologically and Kinetically Distinct Transient Potassium Currents in Cultured Embryonic Mouse Hippocampal Neurons
}

\author{
Rui-Lin Wu and Michael E. Barish \\ Division of Neurosciences, Beckman Research Institute of the City of Hope, Duarte, California 91010
}

Transient potassium currents in mammalian central neurons influence both the repolarization of single action potentials and the timing of repetitive action potential generation. How these currents are integrated into neuronal function will depend on their specific properties: channel availability at the resting potential, activation threshold, inactivation rate, and current density. We here report on the voltage-gated transient potassium currents in embryonic mouse hippocampal neurons dissected at embryonic days 15-16 and grown in dissociated cell culture for up to $3 \mathrm{~d}$.

Two transient potassium currents, A-current and D-current, were isolated based on steady state inactivation and sensitivity to 4-aminopyridine (4-AP) and dendrotoxin (DTx). A-current had an activation threshold of approximately $-\mathbf{5 0}$ $\mathrm{mV}$ and was half-inactivated at approximately $-81 \mathrm{mV}$. A-current relaxations at voltages between -40 and $+40 \mathrm{mV}$ could be fit by single exponential functions with time constants of 20-25 msec; these time constants showed little sensitivity to voltage. In contrast, $D$-current had an activation threshold of between $-\mathbf{4 0}$ and $-30 \mathrm{mV}$ and was half-inactivated at approximately $-22 \mathrm{mV}$. D-current inactivation was voltage dependent; time constants of fitted exponential functions ranged from approximately $7 \mathrm{sec}$ at $-\mathbf{4 0} \mathrm{mV}$ to $200 \mathrm{msec}$ at $+40 \mathrm{mV}$. A slower component of inactivation was also evident. D-current was preferentially blocked by 4-AP $(100 \mu \mathrm{M})$ and DTx (1 $\mu \mathrm{M})$. Operationally, A- and D-currents could be cleanly separated based on conditioning pulse potential and 4-AP sensitivity.

Total transient potassium current amplitude increased during the time that neurons were in culture (recordings were made between $2 \mathrm{hr}$ after dissociation and $3 \mathrm{~d}$ in culture). When normalized for cell capacitance (an index of membrane area), A-current density (pA/pF) decreased and D-current density increased, even during a period between days 1 and 3 when total transient current density remained constant. This observation suggests that $A$ - and $D$-currents may be reciprocally modulated. Since blockade of $D$-current (with $100 \mu \mathrm{M}$ 4-AP) increased both action potential duration and repetitive firing in response to constant current stimulation, long-term modulation of the A-current: D-current ratio may affect the excitability of hippocampal neurons.

\footnotetext{
Received Aug. 20, 1991; revised Jan. 8, 1992; accepted Jan. 13, 1992.

We thank Ms. Sharyn Webb for assistance in preparation of the manuscript. This work was supportcd by funds from the Bcckman Rescarch Institute of the City of Hope. M.E.B. is an Established Investigator of the American Heart Association.

Correspondence should be addressed to Michael E. Barish at the above address. Copyright (C) 1992 Society for Neuroscience $0270-6474 / 92 / 122235-12 \$ 05.00 / 0$
}

Transient potassium currents were first described in invertebrate neuron somas (Hagiwara et al., 1961; Connor and Stevens, 1971 a; Neher, 1971), where they were shown to modulate slow repetitive firing behavior (Connor and Stevens, 1971b). They have since been described in numerous other types of neurons, as well as in cardiac muscle and other excitable cells (for reviews, see Rogawski, 1985; Rudy, 1988), and have been shown to influence multiple additional aspects of electrogenesis. In invertebrate ganglia, a major determinant of electrical individuality of identified neurons is variation in the amplitude and inactivation kinetics of A-current (Serrano and Getting, 1989), and transient potassium currents also influence electrical integration in nonspiking neurons (Mirolli, 1981; Laurent, 1991). In vertebrate neurons, including those of mammalian hippocampus, transient potassium currents have been demonstrated to affect action potential duration and/or repetitive firing during maintained stimulation (see, e.g., Gustafsson et al., 1982; Segal et al., 1984; Halliwell et al., 1986; Nakajima et al., 1986; Stansfeld et al., 1986; Storm, 1987, 1988; Gean and Schinnick-Gallagher, 1989; present results).

Transient outward currents in mammalian and nonmammalian neurons have usually been identified as A-currents by pharmacological and kinetic criteria (Thompson, 1977). These include rapid activation and inactivation, dependence on the holding potential, and sensitivity to 4-aminopyridine (4-AP). In some neurons (see Discussion), an additional class of transient outward potassium current has been described. These currents, termed D-currents, differ from A-currents in showing activation and inactivation at different voltages, slower inactivation during depolarizing voltage steps, and enhanced sensitivity to 4-AP, dendrotoxin (DTx), and mast cell degranulating peptide (MCD peptide) (for reviews, see Dolly, 1988; Moczydlowski et al., 1988; Castle et al., 1989).

Despite the wide distribution of D-currents, there have been few studies in which A- and D-currents have been explicitly identified and separated in the same cell. In adult rat hippocampal neurons, Storm (1988) separated A- and D-currents pharmacologically, and studied the role of D-current in modulating repetitive firing behavior during constant current stimulation. We have investigated further the properties of transient potassium currents in embryonic mouse hippocampal neurons dissociated and grown in culture for up to $3 \mathrm{~d}$. We show below that these currents can be differentiated based on their kinetics and pharmacological sensitivities, and that in these mouse neurons D-currents affect both action potential repolarization and repetitive firing. Further, we observed that the relative proportions of A- and D-currents present in the membrane changed during the $3 \mathrm{~d}$ from embryonic days 15 to 16 (E15-E16) that the neurons were in culture. Such alterations could influence the 
shape of the action potential (which is repolarized by both transient and Ca-dependent potassium currents; Storm, 1987) and thus modulate Ca entry.

A preliminary report of some of these results has appeared (Wu and Barish, 1991).

\section{Materials and Methods}

Cultures. Details of the procedures for preparation and growth of cultures have been modified from previous investigations (Barish et al., 1991). Pregnant mice at E15-E16 were obtained from Simonsen. Embryos were removed and kept at room temperature while hippocampi were isolated (Banker and Cowan, 1977) and stored in HEPES (25 mM)supplemented Hank's balanced salts solution (HBSS; JRH Biosciences) at $37^{\circ} \mathrm{C}$. After sufficient hippocampi had been obtained, they were transferred into dissociation solution [2\% v/v papain solution (Worthington $2 \times$ crystallized), $5.5 \mathrm{~mm}$ cysteine, $25 \mathrm{~mm}$ HEPES in Ca/Mg-free HBSS] for a total of $45 \mathrm{~min}$ at $37^{\circ} \mathrm{C}$, with a change of solution at $15 \mathrm{~min}$. They were then rinsed in trypsin inhibitor solution $[0.8 \mathrm{mg} / \mathrm{ml}$ type II-O chicken egg white trypsin inhibitor (Sigma T-9253) in HBSS] for $5 \mathrm{~min}$, followed by two rinses in culture medium. Cells were then dissociated by gentle trituration with three flame-polished Pasteur pipettes of decreasing diameter, and plated a concentration of $4.8 \times 10^{5} \mathrm{cells} / \mathrm{ml}$ in $125 \mu 1$ droplets onto coated 12 -mm-diameter glass coverslips, to give a final cell density of $5.3 \times 10^{4}$ cells $/ \mathrm{cm}^{2}$. Cells were allowed to settle for $1 \mathrm{hr}$ in the incubator, and the $35-\mathrm{mm}$-diameter dishes were then filled with $3 \mathrm{ml}$ of warm medium. Cultures were treated with $15 \mu \mathrm{M}$ 5-fluoro-2'-deoxyuridine after $24-48 \mathrm{hr}$ to halt overgrowth by glial cells.

The basic culture medium consisted of minimum essential medium (Earle's salts, glutamine-free; Mediatech) supplemented with $\mathrm{NaHCO}_{3}$ to $38 \mathrm{~mm}$ total, $1 \mathrm{~mm}$ pyruvate, glucose to $21 \mathrm{~mm}$ total, $1 \%$ ITS + (insulin, selenium, transferrin; Collaborative Research), 10 mM HEPES, and 2 mu glutamine. To this was added in early experiments $5 \%$ NuSerum IV (Collaborative Research), 5\% fetal bovine serum (HyClone), 10\% non-heat-inactivated equine serum (HyClone or Gemini Bioproducts), and antibiotics. In later experiments, the additions were $10 \%$ NuSerum IV and $10 \%$ equine serum and antibiotics were eliminated. Cultures were grown at $37^{\circ} \mathrm{C}$ in a humidified $7 \% \mathrm{CO}_{2} /$ room air atmosphere.

Coverslips were cleaned and sterilized in $70 \%$ ethanol and coated with $100 \mu \mathrm{g} / \mathrm{ml}$ poly-D-lysine (Sigma P-0899) in $0.1 \mathrm{M} \mathrm{Na-borate} \mathrm{buffer}$ (pH 8.5) for $1 \mathrm{hr}$. They were then rinsed three times with sterile distilled water. In some cases coverslips were additionally coated with $12.5 \mu \mathrm{g} /$ ml laminin in HBSS; a $25 \mu$ drop was placed on the coverslip for 2-3 $\mathrm{hr}$, and the cells in medium were plated directly into this mixture.

Electrophysiological techniques. Conventional whole-cell gigaohm seal recording techniques were employed (Hamill et al., 1981). Recordings were made using an Axopatch 1B amplifier (Axon Instruments); pulse generation, data acquisition, and analysis were performed using a TL-1 interface and the pCLAMP suite of programs (Axon Instruments) running on an AT-type microcomputer. Capacity and leakage subtraction were performed using a combination of analog compensation at the amplifier and a $P /-8$ subtraction protocol. Series resistance compensation was not routinely employed. In test experiments, $50-80 \%$ compensation did not significantly affect the current waveforms; the greatest voltage error for the largest currents is estimated to be $12 \mathrm{mV}$. Currents were typically low-pass filtered (four pole Bessel filter) at $0.5-1 \mathrm{kHz}$, and data were typically acquired at $\mathbf{l}-2 \mathrm{kHz}$. All voltages were compensated for liquid junction potentials.

Electrodes were pulled from methanol-cleaned VWR $75 \mu \mathrm{l}$ borosilicate glass pipettes to resistances of 2-3 M (standard internal and external solutions). The intracellular solution consisted of (in $\mathrm{mM}$ ) $65 \mathrm{KCl}$, $65 \mathrm{KF}, 1 \mathrm{CaCl}_{2}, 2 \mathrm{MgCl}_{2}, 11$ EGTA, and 10 HEPES; $\mathrm{pH} 7.3$. The external solution (based on HBSS) consisted of (in $\mathrm{mM}$ ) $140 \mathrm{NaCl}, 5.8$ $\mathrm{KCl}, 0.8 \mathrm{CaCl}_{2}, 1 \mathrm{MgCl}_{2}, 4.2 \mathrm{NaHCO}_{3}, 5.5$ glucose, and 15 HEPES; $\mathrm{pH}$ 7.3. All external solutions contained $0.5-1 \mu \mathrm{M}$ tetrodotoxin (TTX) to block voltage-gated $\mathrm{Na}$ currents, and $0.5 \mathrm{mg} / \mathrm{ml}$ bovine serum albumin (BSA) to reduce surface tension.

The bath was continuously perfused at $0.5-1 \mathrm{ml} / \mathrm{min}$. Drugs were added either by changing the bath perfusate (and waiting for equilibration), or by changing the solution emerging from a continuously flowing multibarreled puffer pipette positioned close to the cell under study (solution change time, $250 \mathrm{msec}$, estimated from the shift in junction potential between $0.1 \mathrm{M} \mathrm{NaCl}$ and $\mathrm{KCl}$ solutions measured at the cell position). Recordings were made at room temperature $\left(23 \pm 0.5^{\circ} \mathrm{C}\right)$.

Tetrodotoxin was purchased from Calbiochem, and dendrotoxin was purchased from Natural Product Sciences. All other reagents were from Sigma.

\section{Results}

Cultured mouse hippocampal neurons were similar in appearance to those described by Banker and Cowan (1977), and displayed morphologies that could be classified as pyramidal, fusiform, or multipolar using the criteria of Kriegstein and Dichter (1983). Recordings were made from neurons considered pyramidal based on the presence of triangular perikaryon with one prominent apical dendrite, several shorter basilar dendrites, and in many cases spines along the dendrites. These recordings were made in the whole-cell configuration using a $\mathrm{KF} / \mathrm{KCl}$-based internal solution containing EGTA, and a HBSS-based external solution containing TTX. A scrics of control experiments demonstrated that the concentrations of TTX used were sufficient to block all voltage-gated $\mathrm{Na}$ currents (both inactivating and noninactivating), and that $\mathrm{Ca}$ currents (recorded from $\mathrm{Cs}$-perfused cells) were eliminated by high concentrations of internal F (see also Kostyuk et al., 1977; Kay et al., 1986). In a recent review, Storm (1990) described six voltage- and Ca-gated potassium currents in hippocampal pyramidal neurons. Under the recording conditions used here, neither M-current nor either of the two Ca-dependent potassium currents were evident. We confirmed that addition of 200-300 $\mu \mathrm{M}$ Cd or removal of external $\mathrm{Ca}$ did not alter the waveforms of outward currents. As described below, we can account for virtually all outward current by the combination of voltage-gated A-, D-, and K-currents.

\section{Separation of $A$-, $D$-, and $K$-currents}

The traces in Figure 1 demonstrate decomposition of total outward current into A-, D-, and K-currents using varying prepulse potentials and low concentrations $(100 \mu \mathrm{M})$ of 4 -AP. Figure $1 \mathrm{~A}$ shows a matrix of current families recorded at voltages between -50 and $+40 \mathrm{mV}$ following 1 -sec-long conditioning pulses from the holding potential $(-80 \mathrm{mV})$ to $-120 \mathrm{mV}\left(V_{c}=-120 \mathrm{mV}\right)$ or 500 -msec-long pulses to $-40 \mathrm{mV}\left(V_{c}=-40 \mathrm{mV}\right)$ in normal external solution (left column) or in the presence of $100 \mu \mathrm{M}$ 4-AP (right column). Figure $1 B$ shows the results of point-bypoint subtractions designed to isolate $A$ - and $D$-currents. Traces are shown on the left, and $I-V$ relations for these currents on the right. A-current was taken to be the current sensitive to conditioning depolarizations to $-40 \mathrm{mV}$, and thus the appropriate subtractions were $a-c$ and $b-d$. Similar fast-inactivating currents were obtained in normal solution and in the presence of $100 \mu \mathrm{M} 4$-AP, a pattern indicating that A-currents were insensitive to low concentrations of 4-AP. They were blocked completely by higher concentrations (2-3 $\mathrm{mm}$; not shown). D-current was taken to be the current sensitive to 100 $\mu \mathrm{M}$ 4-AP, and the appropriate subtractions were thus $a-b$ and $c-d$. Similar currents were obtained when the currents subtracted followed conditioning depolarizations to -120 or -40 $\mathrm{mV}$. The current recorded following a prepulse to $-40 \mathrm{mV}$ in the presence of 4-AP $(d)$ was taken to be K-current, as it showed minimal inactivation, and was blocked by $30 \mathrm{mM}$ tetraethylammonium (not shown).

A- and D-currents could be further distinguished by the differential sensitivity of D-current to DTx and 4-AP. The traces in Figure $2 A$ compare the effects of $100 \mu \mathrm{M} 4-\mathrm{AP}$ and $1 \mu \mathrm{M}$ DTx on A- and D-currents recorded during an 8-sec-long voltage step to $+20 \mathrm{mV}$. DT $\mathrm{x}$ at $1 \mu \mathrm{M}$ blocked virtually all slowly inactivating current while sparing the initial fast transient A-current, and in 
A

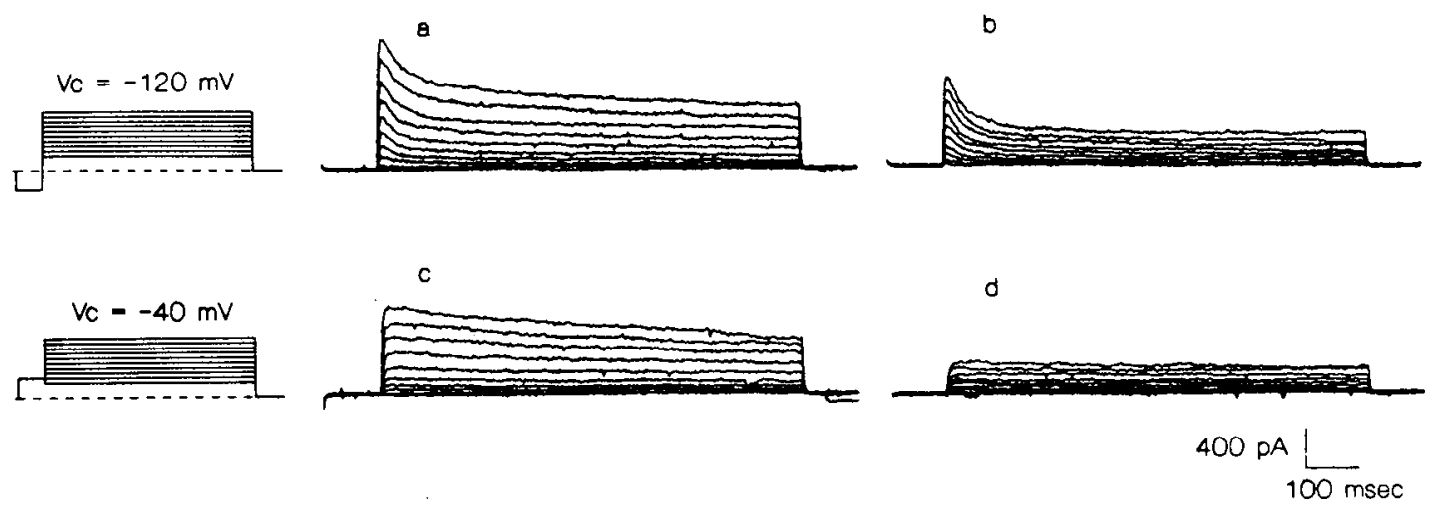

$\mathrm{B}$

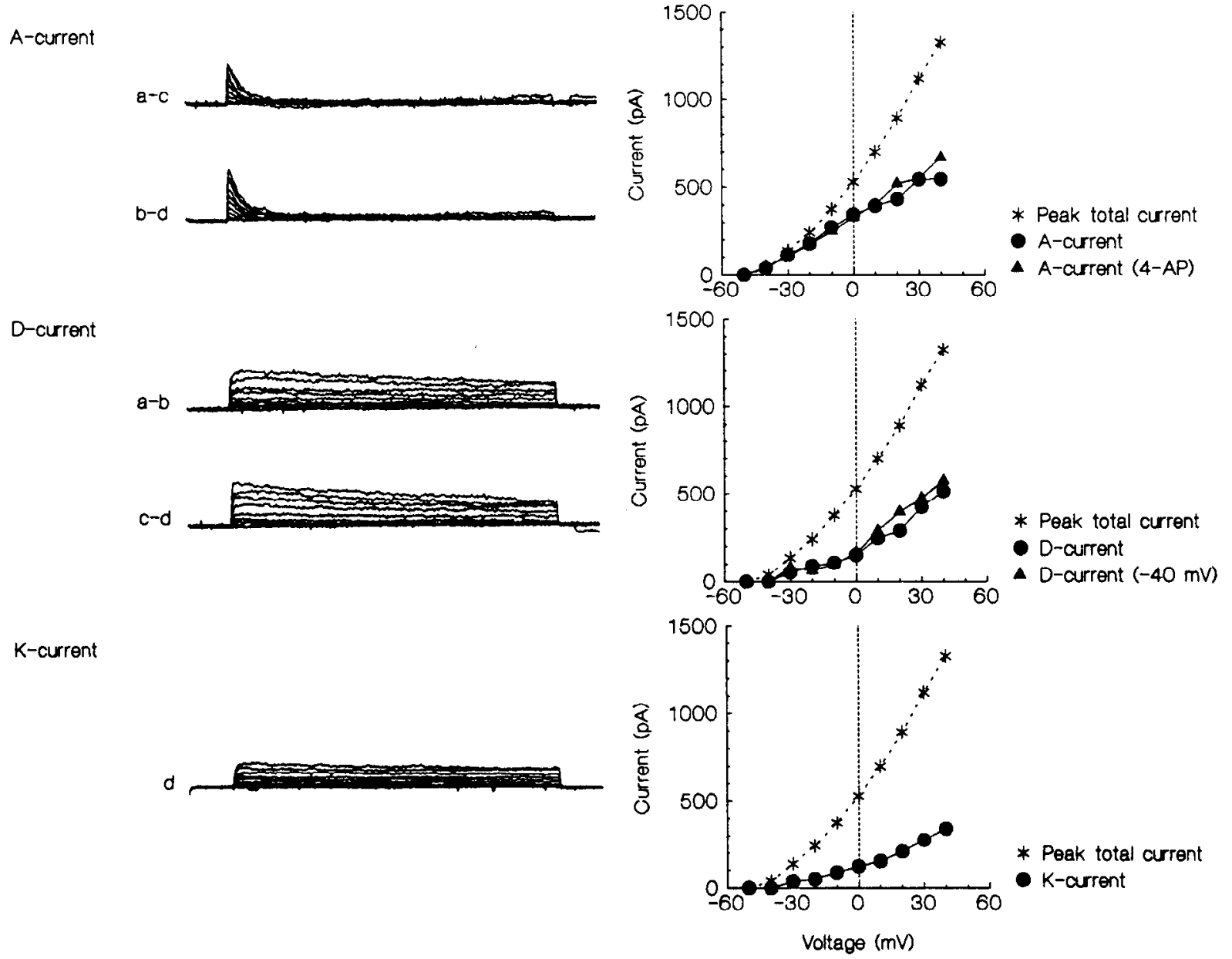

Figure 1. Separation of A-, D-, and K-currents based on voltage dependence of inactivation and sensitivity to 4-AP. $A$, Matrix of total outward currents recorded during voltage steps from a holding potential of $-80 \mathrm{mV}$ under four conditions: $a$, following a 1 -sec-long conditioning hyperpolarization to $-120 \mathrm{mV} ; b$, same as $a$ but in the presence of $100 \mu \mathrm{M} 4-\mathrm{AP} ; c$, following a 500 -msec-long conditioning depolarization to $-40 \mathrm{mV}$; $d$, same as $c$ but in the presence of $100 \mu \mathrm{M}$ 4-AP. $B$, Subtractions of current traces shown in $A$ to separate the individual currents. A-current was defined as the current sensitive to conditioning depolarization to $-40 \mathrm{mV}$, and D-current as the current sensitive to $100 \mu \mathrm{M} 4$-AP. Currents resulting from each of the two possible subtractions in the matrix are shown, along with plots of amplitude versus voltage in comparison to total peak potassium current. K-current was taken to be the potassium current remaining after removal of A-and D-currents, as shown in $d$. All traces in this figure were taken from the same cell. Similar results were obtained in 24 different cells analyzed in this manner.

its actions was thus similar to 4-AP at $100 \mu \mathrm{M}$. We observed only minimal block of D-current by 100-500 nM DTx. Selective block of D-current by 1-2 $\mu \mathrm{M}$ DTx was observed in five of five neurons examined.
The 4- $\Lambda \mathrm{P}$ - and DTx-sensitive currents isolated by subtraction of the traces in Figure $2 A$ are shown below in Figure $2 B$. The inactivating phases could be fit by single exponential functions with time constants of 2100-2200 msec, values somewhat larger 
A

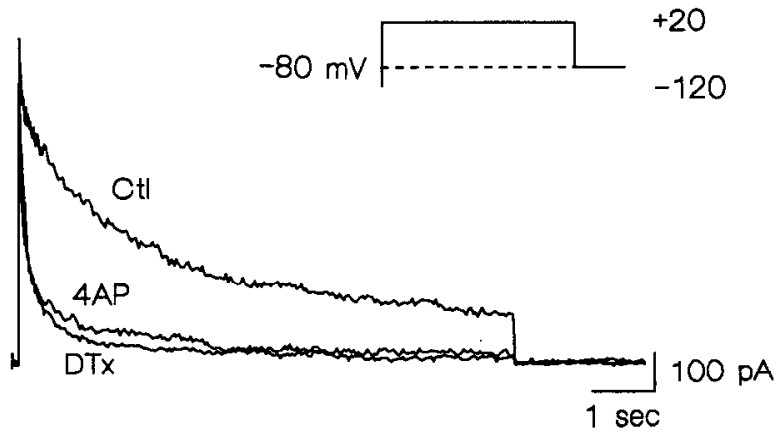

B

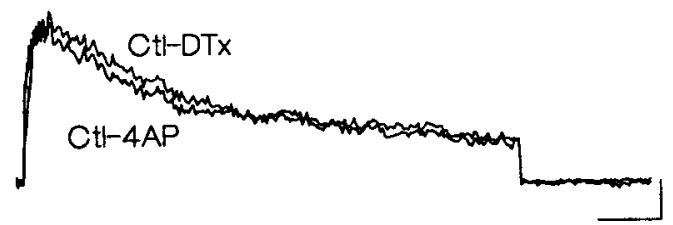

Figure 2. DTx $(1 \mu \mathrm{M})$ and 4-AP $(100 \mu \mathrm{M})$ block similar slowly inactivating transient potassium currents. The currents in $A$ were recorded during 8-sec-long depolarizations to $+20 \mathrm{mV}$ following 1-sec-long conditioning hyperpolarizations to $-120 \mathrm{mV}$. DT $x$ and 4-AP were applied using a multibarreled puffer pipette; currents recovered during the wash in control solution that separated application of the two drugs. Difference currents between control and currents recorded in the presence of 4-AP and DTx are shown in $B$. Both agents selectively blocked slowly inactivating $D$-current while sparing the more rapidly activating and inactivating A-current.

than those seen when currents recorded during shorter steps to the same voltage were similarly fit. This observation suggests that there are slow components to D-current inactivation not reflected in the short-duration relaxations analyzed in Figure 5.

Standard protocols were adopted for isolation of A- and D-currents. Normally, A-current was evaluated in the absence of aminopyridines or other blockers, and D-current was taken to be the $(100 \mu \mathrm{M}) 4-\Lambda \mathrm{P}$-sensitive current recorded after conditioning hyperpolarizations to $-120 \mathrm{mV}$. The effects of altering conditioning pulse potential were fully reversible. Treatment with 4 -AP could be reversed to approximately $80 \%$ of control after $10 \mathrm{~min}$ of superfusion with 4-AP-free solutions.

\section{Characterization of the two transient potassium currents}

Reversal potential. A series of experiments was performed to test for possible differences in the potassium sensitivities of Aand D-currents. The reversal potential for transient outward current was measured by depolarizing cells exhibiting both Aand D-currents to $+20 \mathrm{mV}$ for 10 or $100 \mathrm{msec}$ and then determining the zero current potential for total whole-cell tail current measured 5-7 msec after repolarization to test voltages between -120 and $0 \mathrm{mV}$. Recordings were made following conditioning pulses to $-120 \mathrm{mV}$ or to $-40 \mathrm{mV}$, and in external solutions containing 5.8 (normal), 12 , and $48 \mathrm{~mm} \mathrm{~K}$ (substituted for $\mathrm{Na}$ on an equimolar basis). Measurements were thus made for currents composed of both A- and D-current, or D-current only, with a minority component of K-current also contributing to the determination of reversal potential (approximately 30\% of total peak potassium current is contributed by K-current; see Fig. 1). As indicated by the data shown in Figure 3, there was

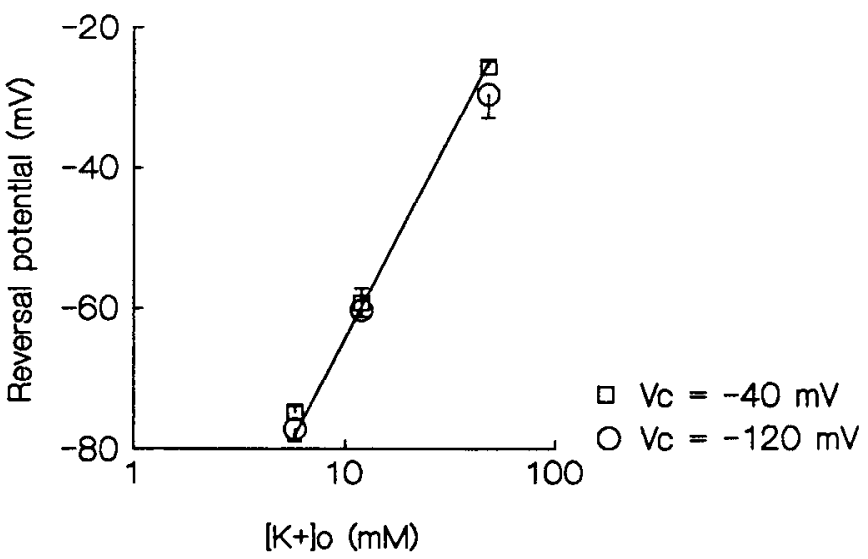

Figure 3. Reversal potentials for tail currents recorded after 10-mseclong depolarizations to $+20 \mathrm{mV}$ following conditioning polarizations to $-120 \mathrm{mV}$ (to activate both A-, D-, and K-currents) or to $-40 \mathrm{mV}$ (to activate $\mathrm{D}$ - and $\mathrm{K}$-currents only), and comparison to the potassium equilibrium potential $\left(E_{\mathrm{k}}\right.$, solid line). The data shown are mean $\pm \mathrm{SEM}$ for three or four determinations. The reversal potentials at each potassium concentration were not significantly different (paired two-tailed $t$ test), and corresponded closely to $E_{\mathrm{K}}$ computed from the Nernst relation for $\left[\mathrm{K}^{+}\right]_{i}=130 \mathrm{~mm}$ and $\left[\mathrm{K}^{+}\right]_{o}=5.8,12$, or $48 \mathrm{~mm}$.

no significant difference between the reversal potentials determined for $V_{c}=-120 \mathrm{mV}$ and $V_{c}=-40 \mathrm{mV}$. Similar results were obtained for tail currents recorded following 100 -mseclong activating depolarizations. These observations suggest that both $\mathrm{A}$ - and D-current have similar high selectivities for potassium. Further, good agreement of the measured reversal potentials with the Nernst potentials calculated for the internal and external potassium concentrations utilized suggests that currents carried by other ions were not present under the recording conditions utilized.

Voltage dependencies of activation and inactivation. Currents recorded using two-pulse voltage protocols to determine the activation and inactivation properties of $\mathrm{A}$ - and D-currents are shown in Figure $4 A$, and the activation and inactivation curves obtaincd from thesc (open circles) and multiple cells (solid symbols; mean \pm SEM) are shown in Figure $4 B$. These recordings were made from selected cells exhibiting predominantly A-current or D-current (see caption). Steady-state inactivation was determined by measuring current availability following 700 msec-long conditioning steps to voltages between -120 and 0 $\mathrm{mV}$, and current activation was measured during these same steps. Activation and inactivation curves were fit with Boltzmann relations of the forms and with the parameters given in the caption.

The A-current activation threshold (approximately $-50 \mathrm{mV}$ ) was $10-20 \mathrm{mV}$ negative to that for $\mathrm{D}$-current (between -40 and $-30 \mathrm{mV}$ ); these values are just positive to the resting potential for these cells (between -80 and $-60 \mathrm{mV}$ ). The half-inactivation voltage for A-current was $-81.4 \pm 1.4 \mathrm{mV}$ (mean \pm $\mathrm{SEM}, n=5)$, while for D-current it was $-21.5 \pm 4.5 \mathrm{mV}(n=$ 4). A substantially greater proportion of D-current as compared to A-current will thus be available for activation during voltage excursions from the resting potential.

Inactivation time courses. Representative records used to determine inactivation time constants are shown in the upper $(A$ and $B$ ) and lower portions $(C-E)$ of Figure 5. These records were taken from cells exhibiting predominantly A- or D-currents 
A
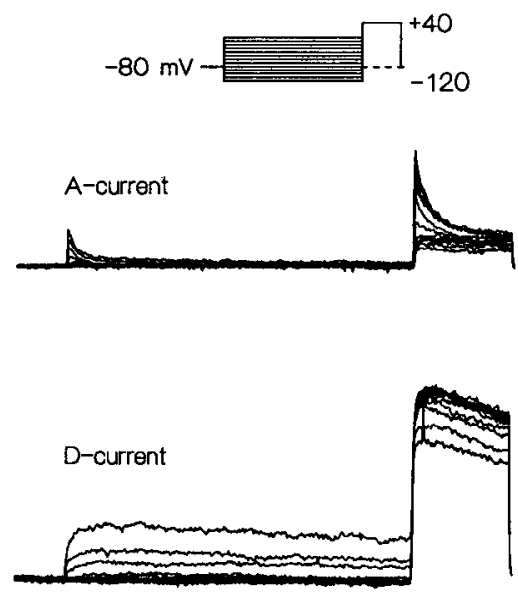

$200 \mathrm{pA}$

$100 \mathrm{msec}$
B
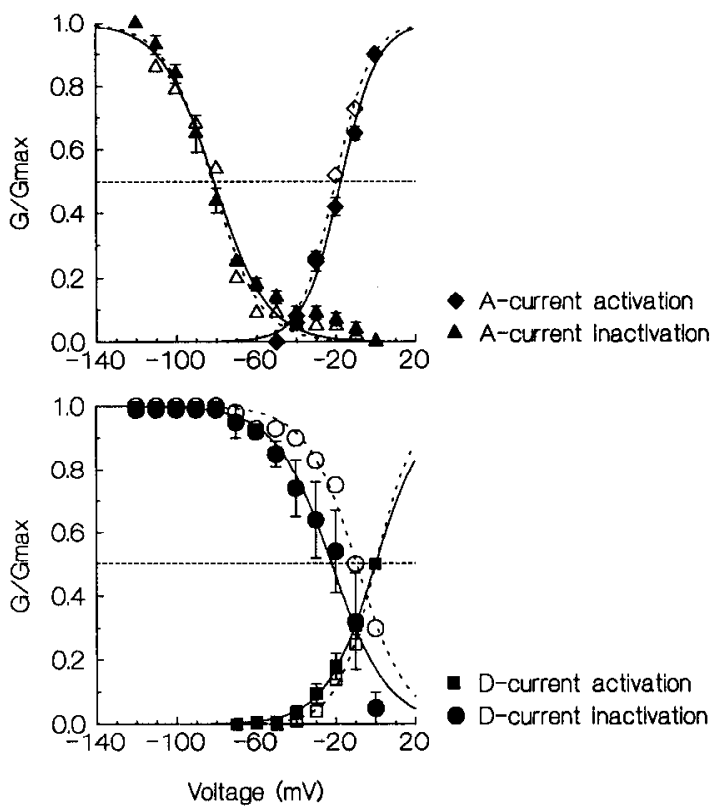

Figure 4. Activation and steady state inactivation versus voltage relations for A- and D-currents. $A$, For determination of steady state inactivation, current availability was assayed by test depolarizations to $+40 \mathrm{mV}$ following 700 -msec-long conditioning steps to voltages between -120 and 0 $\mathrm{mV}$, and expressed as relative conductance $\left(G / G_{\mathrm{max}}\right)$. Activation was detcrmincd from the amplitudes of transient currents during the conditioning pulse, and their computed chord conductance versus voltage $(G-V)$ relations were normalized relative to similar curves computed for the currents shown in Figure 1 in which $G$ reached a maximum. These recordings were made from cells expressing only A-current (on day 0 ) or D-current (on day 3). $B$, Plots of relative activation and inactivation (expressed as $G / G_{\max }$ ) for A-current (above) and D-current (below). Values for the currents presented in $A$ are shown using open symbols (with fitted Boltzmann relations as broken lines), and mean ( \pm SEM) values are shown using solid symbols (with fitted Boltzmann relations as continuous lines). Numbers of cells $(n)$ are 5 for A-current activation and inactivation, 4 for D-current activation, and 3 for D-current inactivation. The plots of relative conductance versus voltage in $B$ were fit with Boltzmann relations of the form $G / G_{\max }=1 /\left\{1+\exp \left[\left(V-V_{y_{2}}\right) / k\right]\right\}$ for inactivation and $G / G_{\max }=1 /\left\{1+\exp \left[-\left(V-V_{1_{2} / 2}\right) / k\right]\right\}$ for activation. Parameters for the fits to values determined for the currents shown in $A$ : A-current activation: $V_{1 / 2}=-20 \mathrm{mV}, k=9$. A-current inactivation: $V_{1 / 3}=-82 \mathrm{mV}, k=12$. D-current activation: $V_{1 / 2}$ $=0 \mathrm{mV}, k=10$. D-current inactivation: $V_{1 / 2}=-10 \mathrm{mV}, k=13$. Parameters for the fits to mean values: A-current activation: $V_{1 / 2}=-17 \mathrm{mV}, k=$ 9. A-current inactivation: $V_{1 / 2}=-81 \mathrm{mV}, k=13$. D-current activation: $V_{1 / 2}=0 \mathrm{mV}, k=13$. D-current inactivation: $V_{1 / 2}=-22 \mathrm{mV}, k=14$. Recordings in which the properties of A- and D-current were characterized were made from neurons of different ages expressing predominantly $r \mathrm{re}$ or the other current. As described, the proportion of total potassium current attributable to A- or D-current changed during the $3 \mathrm{~d}$ that the neurons were in culture. Thus, at early times some cells expressed almost exclusively A-current while after approximately $3 \mathrm{~d}$ transient potassium current in some cells was dominated by D-current. Such ncurons were sclected for this and other analyses.

(see Fig. 4 caption). A- and D-current relaxations during excursions to activating voltages were fit with single exponential functions (Fig. $5 A, C$ ), and D-current inactivation at voltages negative to the activation threshold was determined using a twopulse protocol $(D 1, D 2)$. The time constants of A-current inactivation did not vary systematically with voltage and were approximately $20-25 \mathrm{msec}$ at voltages between -40 and +40 $\mathrm{mV}$ (Fig. 5B; open symbols mark data for the traces shown in $A$ and solid symbols indicate mean $\pm \mathrm{SEM}$ ). In contrast, D-currents inactivated much more slowly than A-currents, and with time constants that were more rapid at more positive voltages, varying from approximately $7 \mathrm{sec}$ at $-40 \mathrm{mV}$ to $200 \mathrm{msec}$ at $+40 \mathrm{mV}$ (Fig. $5 E$ ). D-currents showed an additional slower inactivation that was evident during seconds-long voltage steps (see above).

Both A- and D-currents recovered from inactivation with time courses that could be approximated by single exponential functions. As illustrated in Figure 6, recovery from inactivation was assayed using a three-pulse protocol in which an inactivating pulse to $+40 \mathrm{mV}$ was followed by an interval of varying voltage and duration, and then a step to $+40 \mathrm{mV}$ for assay of available current. Time constants for both A-and D-currents ranged from
80 to $200 \mathrm{msec}$ between -120 and $-60 \mathrm{mV}$, with A-current recovery consistently more rapid. Both currents recovered more rapidly at more negative voltages.

\section{Changes in A- and D-current expression during culture}

Neurons were examined for changes in the expression of potassium currents during the first $3 \mathbf{d}$ after dissociation and culture on E15-E16. Typical families of outward currents recorded on days 0 (the day of dissociation), 1, 2, and 3 are shown in Figure $7 \mathrm{~A}$. Both peak and steady state current amplitudes and total cell capacitance increased during the period days $0-2$, and reached a plateau between days 2 and 3 , as shown in the upper portion of Figure $7 B$. The same data normalized to cell capacitance and expressed as specific current (current density expressed as $\mathrm{pA}$ $\mathrm{pF}$ ) are plotted in the lower portion of Figure $7 B$. Specific peak and steady state current increased during the first day in culture, and then remained stable over the next $2 \mathrm{~d}$.

During this period spanning days $1-3$ in which peak current density remaincd approximately constant, current waveforms changed such that slowly inactivating outward currents dominated at longer times in culture (Fig. $7 \mathrm{~A}$ ). The change in waveform suggested a shift in the relative contributions of $\mathrm{A}$ - and 

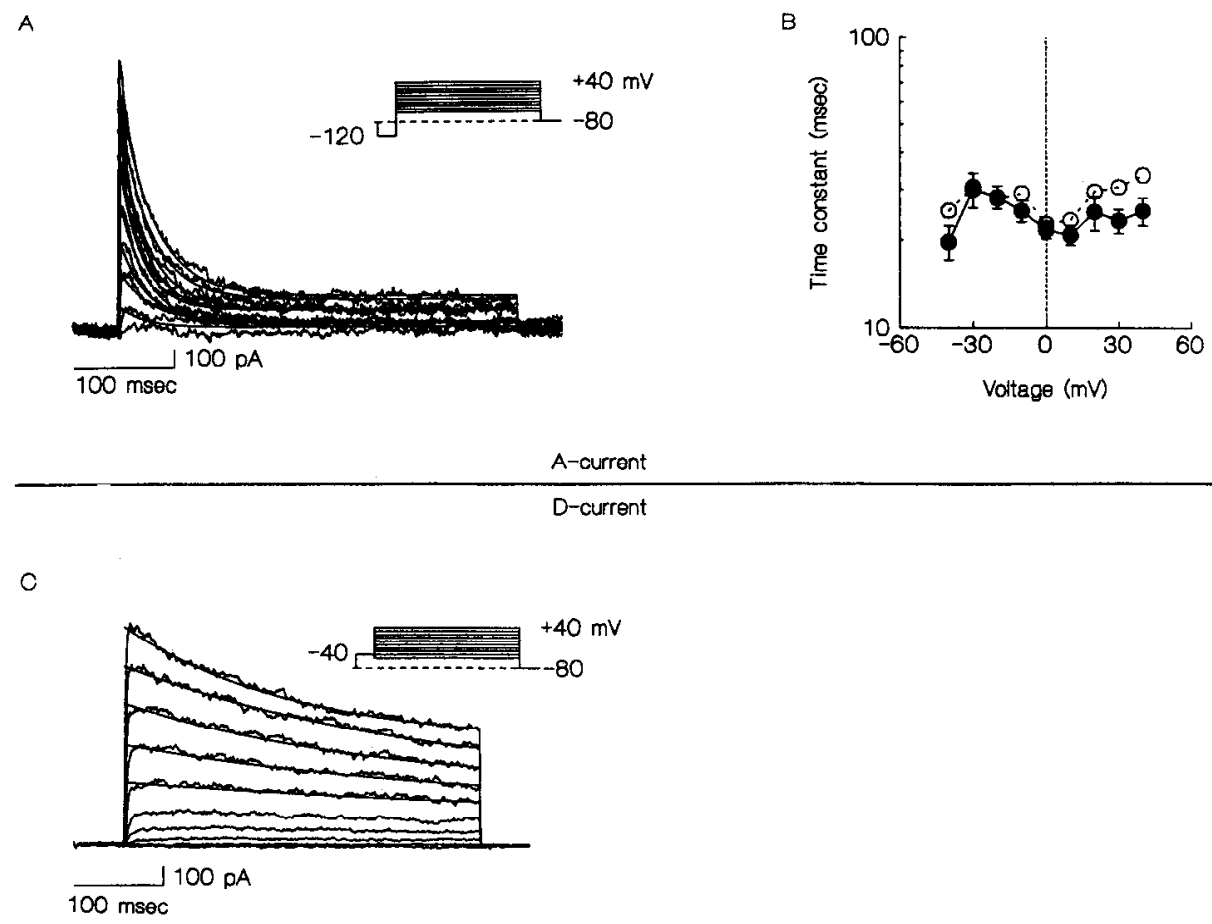

D1

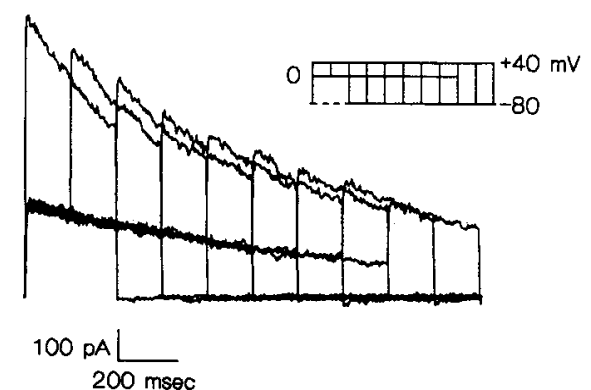

$200 \mathrm{msec}$

E

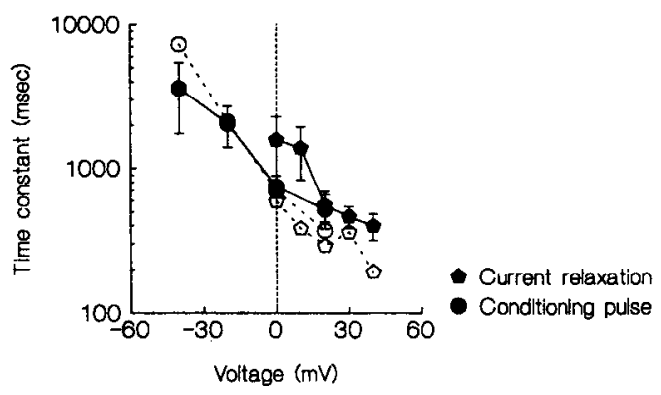

Figure 5. Inactivation time course for A-current $(A$ and $B)$ and D-current $(C$ $E)$. Data were taken from cells expressing predominantly A- or D-current. For $\Lambda$-current, single exponential functions (plus an offset) were fit to the decaying phases of each trace $(A)$, and the time constants of these relaxations plotted on semilogarithmic axes against voltage $(B)$. Open symbols mark values for the cell shown in $A$; solid symbols are mean $\pm \mathrm{SEM}, n=6$ cells. For D-current, either traces recorded at voltages between 0 and $+40 \mathrm{mV}$ were fit with single exponential functions $(C)$ or current availability measured after varying intervals at voltages between -40 and $+20 \mathrm{mV}$ (using test steps to $+40 \mathrm{mV}$ ) was fit with single exponential functions ( $D 1$ and $D 2)$. In $E$, open symbols mark values determined for the cell illustrated in $C$ and $D 1,2$; solid symbols are mean \pm SEM, $n=6$ cells for current relaxation data or 4 cells for conditioning pulse data.
D2

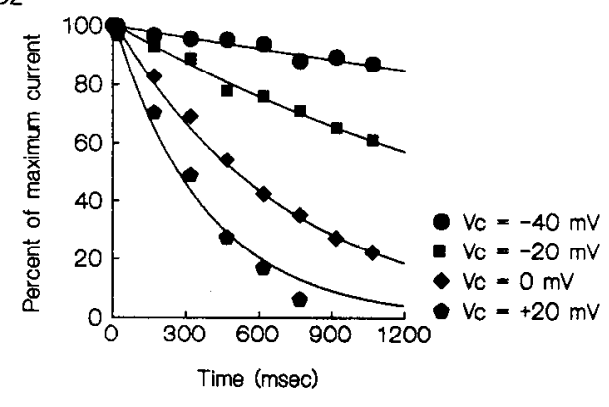

D-current to total potassium current, and this possibility was assessed using two separate schemes.

In one set of measurements, the percentage of total current assigned to A-, D-, or K-currents was determined by separating individual currents using the conditioning voltage and pharmacological criteria outlined in Figure 1. The percentage contributions of these currents to total outward current recorded at a test voltage of $+40 \mathrm{mV}$ is shown in Figure $7 C$. A- and D-currents over the period days $0-3$ changed reciprocally, with the A-current percentage decreasing from approximately $90 \%$ on day 0 to $40 \%$ by day 3 , while the $D$-current percentage increased in parallel. The K-current percentage remained approximately constant.

The second determination was done by analysis of steady state inactivation curves for transient potassium currents. Figure $8 \mathrm{~A}$ shows currents recorded using a two-pulse voltage protocol to measure the voltage dependence of transient potassium current availability at a test potential of $+40 \mathrm{mV}$. As in Figure 7, current relaxations were slower in older cells. Figure $8 B$ shows plots of $I / I_{\max }$ during the test voltage step as a function of the 
A
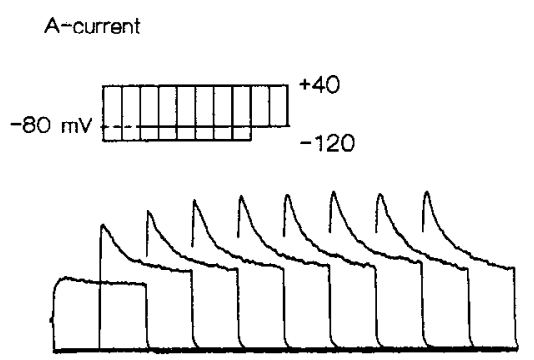

$400 \mathrm{pA}$ $80 \mathrm{msec}$

D-current
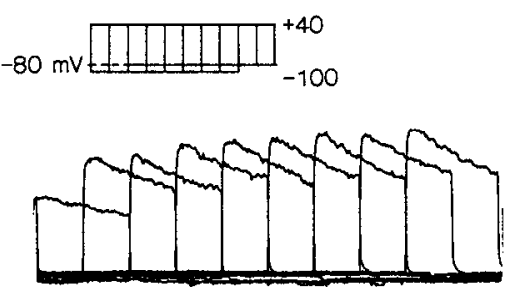

200 pA $200 \mathrm{msec}$

B

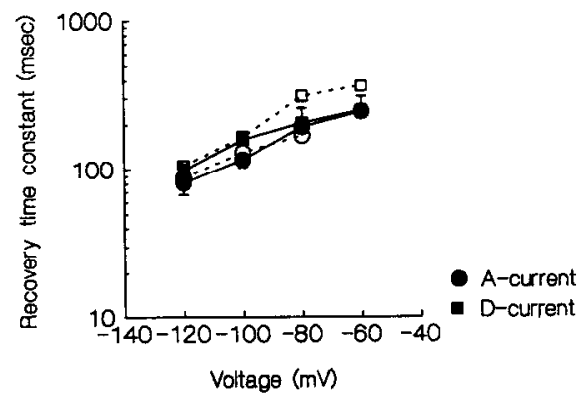

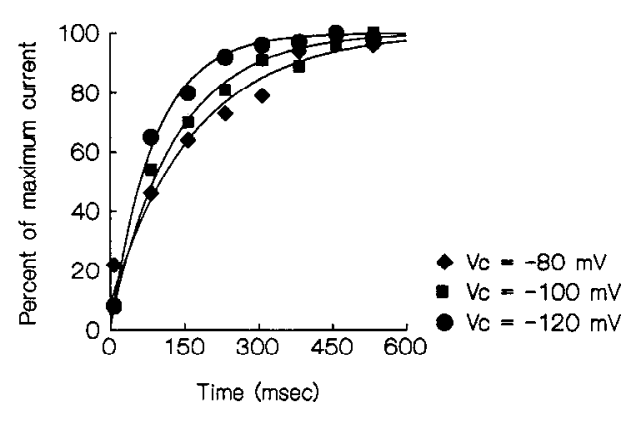

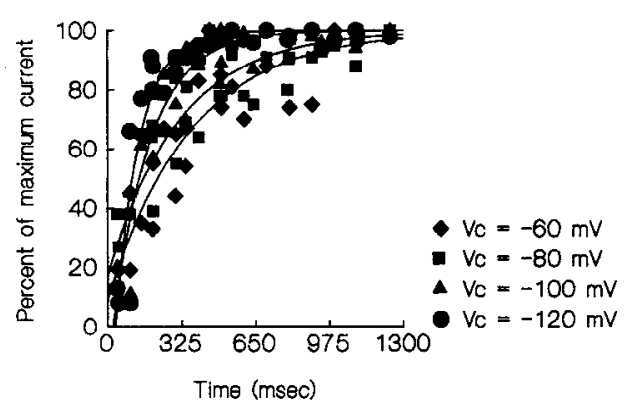

Figure 6. Recovery of A- and D-currents from inactivation. $A$, For both $\mathrm{A}-$ and D-currents, 1-sec-long voltage steps to $+40 \mathrm{mV}$ to inactivate all transient currents were followed by steps of varying durations to voltages between -120 and $-80 \mathrm{mV}$ (for A-current) or -60 $\mathrm{mV}$ (for D-current). The magnitude of available $\mathrm{A}$ - or D-current was then determined during a test voltage step to $+40 \mathrm{mV}$. Records showing A-current recovery at $-80 \mathrm{mV}$ and $\mathrm{D}$-current recovery at $-100 \mathrm{mV}$ are shown on the left panels. Recovery curves at various voltages were fit with single exponential functions (right panels). B, Plots of recovery time constant versus voltage for the records shown in $A$ (open symbols), and mean \pm SEM (solid symbols; $n=$ 4 for A-current and 3 for D-current). preceding conditioning potential. The data were fit with the sum of two Boltzmann relations (solid line) representing the contribution of A- or D-current inactivation to the overall waveform. The parameters of these Boltzmann relations (broken lines as indicated) were similar to those evaluated for A- and D-currents in Figure 3 (see caption) and were fixed. When the relative contributions of A- and D-current components were varied, the steady state inactivation data for each day could be well fit by the sum of these two Boltzmann relations. This pattern is consistent with a change in the relative proportions of $A$ - and D-currents, with the properties of the currents not changing significantly during this period.

Quantitative estimates of the proportions of relaxing currents due to A-current evaluated using these two procedures were similar. By measurement of currents separated as in Figure 1, the contribution of A-current to total potassium current was $89 \%$ on day $0,61 \%$ on day $1,41 \%$ on day 2 , and $38 \%$ on day 3. By fitting steady state inactivation curves, the A-current contribution to relaxing potassium current was $81 \%$ on day $0,69 \%$ on day $1,34 \%$ on day 2 , and $31 \%$ on day 3 .

A further indication that the change in steady state inactivation parameters during the period days $0-3$ was due to in- crease in the proportion of D-current in the membrane is shown in Figure 9. Currents recorded from a day 2 neuron using a twopulse protocol under control conditions, and in the presence of $100 \mu \mathrm{M} 4-\mathrm{AP}$, are shown in Figure $9 A$. In Figure $9 B, I / I_{\max }$ is plotted for these two sets of traces, and for cells on day 0 (when A-currents predominate). At voltages negative to $-60 \mathrm{mV}$, the plots for day 0 neurons and day $2+4-\mathrm{AP}$ neurons are virtually identical, a result indicating that the properties of the day 2 cell were derived from the coexistence of $(100 \mu \mathrm{M})$ 4-AP-resistant and -sensitive components. At more positive voltages, the plots diverge because of the contribution of $\mathrm{D}$-current to transient potassium current in the (untreated) day 0 neurons.

\section{$D$-current contribution to the action potential waveform}

We examined the contribution of D-current to the Na-dependent action potential recorded using the normal $\mathrm{KCl} / \mathrm{KF}$-based intcrnal solution. As shown in Figure $10 \mathrm{~A}, 100 \mu \mathrm{M}$ 4-AP increased repetitive firing in response to constant current stimulation. Further, 4-AP also increased action potential duration, as shown in Figure $10 B$ where the rising phases of the first two action potentials recorded in response to identical $+3.5 \mathrm{pA}$ current injections have been aligned. 
A

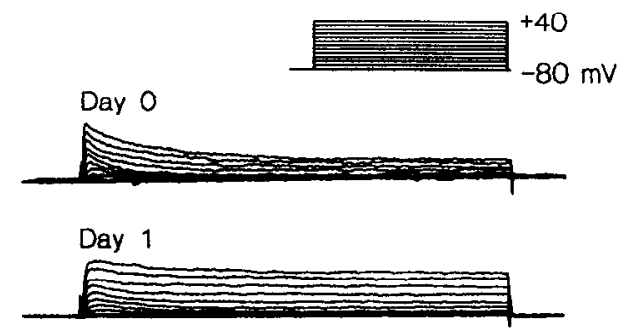

Day 2

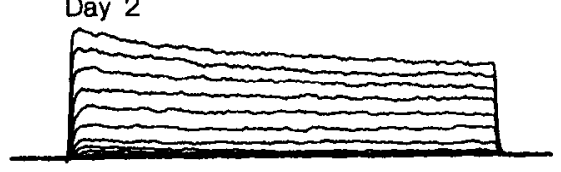

Day 3

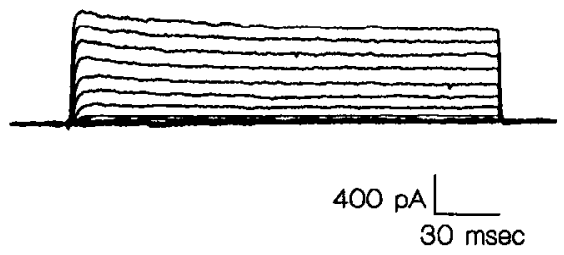

O

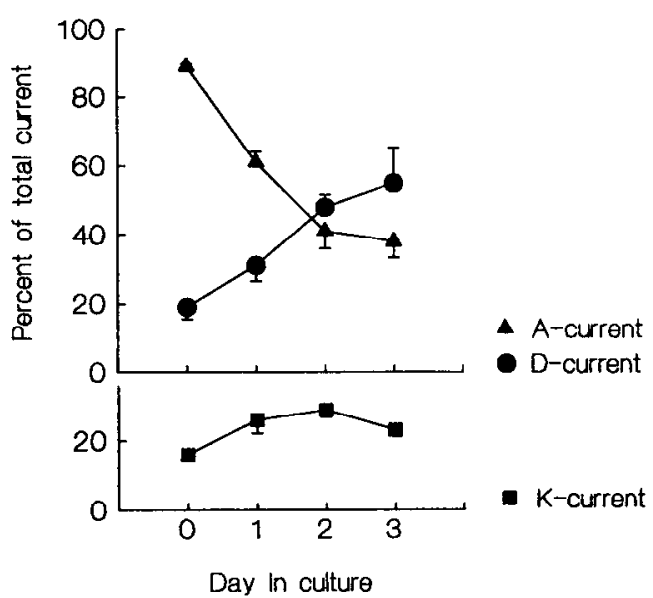

B
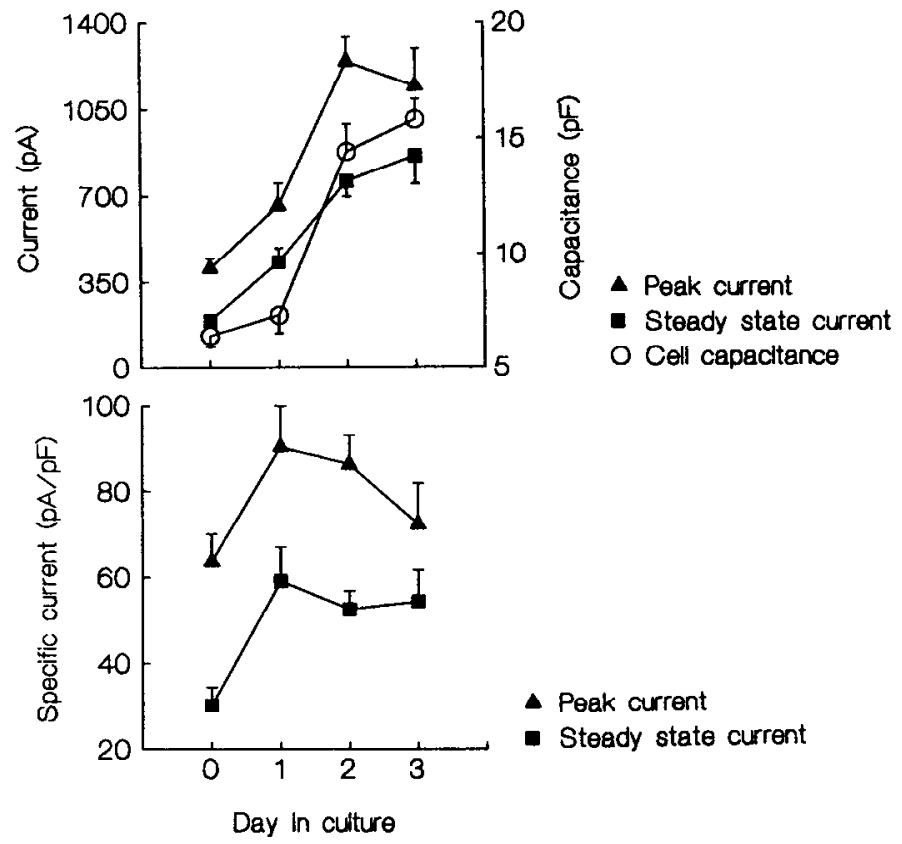

Figure 7. Changes in A-, D-, and K-currents during the first $3 \mathrm{~d}$ of culture, evaluated from records of whole-cell current and separation as illustrated in Figure 1. $A$. Potassium currents recorded during steps to voltages between -80 and $+40 \mathrm{mV}$ from $-80 \mathrm{mV}$. Day 0 refers to the day of culture; recordings were made after allowing the cells to settle onto the substrate for $2-3 \mathrm{hr}$. B. Relationship between increases in potassium current amplitude and changes in membrane area. The upper panel shows mean peak and steady state current amplitudes at $+40 \mathrm{mV}$ (solid triangles and squares) and total cell capacitance (open circles) for cells in culture for up to $3 \mathrm{~d}$. Data are mean $\pm \mathrm{SEM} ; n=9$ for day 0,10 for day 1,8 for day 2 , and 9 for day $3 ; n$ for capacitance $=12$ for day 0,6 for day 1,13 for day 2 , and 10 for day 3 . The lower panel shows mean ( \pm SEM) peak and steady state currents normalized to cell capacitance $(\mathrm{pA} / \mathrm{pF})$, calculated for the cells above. $C$, Changes in relative contributions of $\mathrm{A}$-, D-, and $\mathrm{K}$-currents to total potassium current. Individual currents werc isolated based on holding potential and sensitivity to $100 \mu \mathrm{M} 4-\mathrm{AP}$. The currents sum to slightly more than $100 \%$ because each current was measured at its maximum, and these occurred at slightly different points in the overall waveform. Data are mean \pm SEM (when larger than the symbol); $n=9$ for day 0,20 for day 1,9 for day 2 , and 10 for day 3 .

\section{Discussion}

We have characterized two transient potassium currents in cultured embryonic mouse hippocampal neurons: A- and D-currents. These currents differ in their voltage dependencies of activation and inactivation, and in their sensitivities to 4-AP and DTx. Schemes for their separation in current- and voltageclamp experiments were outlined. Further, reciprocal changes in the densities of A- and D-currents during the first $3 \mathrm{~d}$ after culture at E15-E16 were described that suggest potential modulation of the A-current : D-current ratio in more mature neurons.

\section{Distribution of D-currents}

D-currents, or currents showing the properties of D-currents as defined above, have been observed in many mammalian neurons. They have not always been explicitly identified because they are often found with A-currents, and separation of A-and D-currents requires titration of 4-AP or detailed evaluation of steady state inactivation curves (see udy, 1988). Among the neurons in which D-currents have been identified or observed are rat visceral sensory (nodose) neurons (Stansfeld et al., 1986, 1987), rat dorsal root ganglion neurons (Stansfeld and Feltz, 1988; Stansfeld et al., 1991), rat hippocampal neurons (Gus- 
A
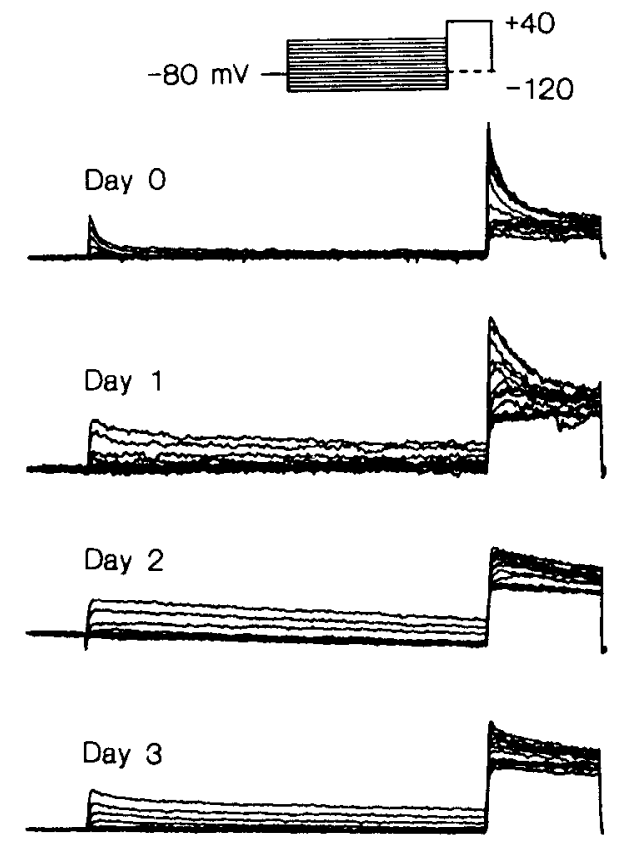

200 pA (Days 0 and 1) $400 \mathrm{pA}$ (Days 2 and 3 )

$100 \mathrm{msec}$
B
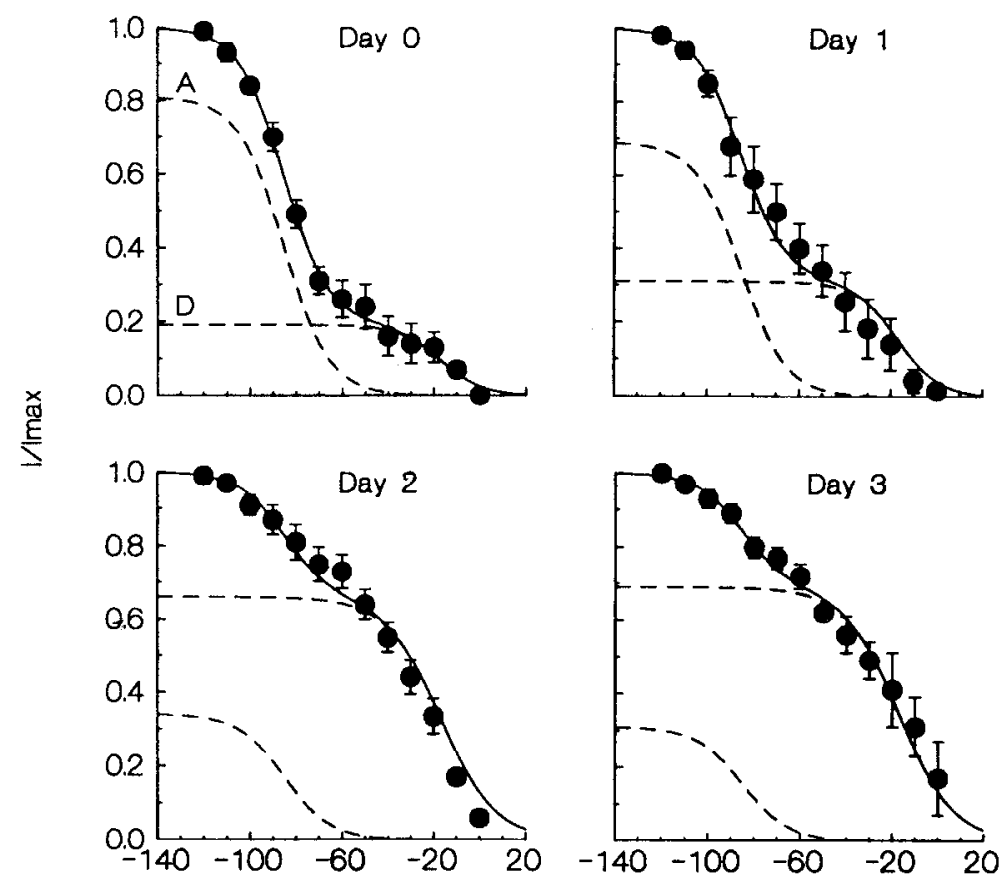

Voltege $(m \mathrm{~m})$

Figure 8. Changes in the contributions of A- and D-currents to total relaxing current during the first $3 \mathrm{~d}$ in culture, evaluated from plots of steady state inactivation versus voltage. $A$, Currents recorded at $+40 \mathrm{mV}$ after 1 -sec-long conditioning voltage steps to voltages between -120 and $0 \mathrm{mV}$ on the days indicated. $B$, Plots of the relative amplitudes $\left(I / I_{\max }\right)$ of relaxing potassium currents $\left(I_{\text {peak }}-I_{\text {steady state }}\right)$ versus conditioning voltage. Data are mean $\pm \mathrm{SEM} ; n=6$ for day 0,6 for day 1,9 for day 2, and 6 for day 3 . Fach of these plots was fit with the sum of Boltzmann relations appropriate for A- and D-currents. Each is indicated by the broken lines, and their sum by the solid lines. The Boltzmann parameters used in computing these curves were derived by fitting the data for day 1 , and were $V_{1 / 2}=-85 \mathrm{mV}$ and $k=10$ for $\mathrm{A}$-current and $V_{1 / 2}=-17 \mathrm{mV}$ and $k=$ 12 for D-current. These parameters were fixed, and only the relative portions of the two Boltzmann relations were varicd in fitting the data in $B$.

tafsson et al., 1982; Halliwell et al., 1986; Storm, 1987, 1988), rat neostriatal neurons (Surmeier et al., 1989, 1991), and rat amygdala neurons (Gean and Schinnick-Gallagher, 1989). In some other neurons, dual transient potassium currents have been observed, but separation of the two has not fit the A- and D-current pattern described above [e.g., histamine neurons in rat hypothalamus (Greene et al., 1990), cal layer V pyramidal neurons (Spain et al., 1991)]. In other cells, only one class of transient potassium current has been reported [e.g., neonatal rat motoneurons (Takahashi, 1990), cerebellar granule cells (CullCandy et al., 1989), cultured rat neocortical neurons (Ahmed, 1988; Zona et al., 1988)]. Some investigations of cultured or acutely dissociated hippocampal neurons, or neurons in slices, have reported the presence of A-but not D-type transient potassium currents (Segal and Barker, 1984; Zbicz and Weight, 1985; Neumann et al., 1987).

\section{Comparison with other transient potassium currents}

A-currents in embryonic mouse hippocampal neurons were similar to those described in other preparations of hippocampal neurons, including rat neurons in culture and in slice, and acutely isolated guinea pig neurons (Gustafsson et al., 1982; Segal and Barker, 1984; Segal et al., 1984; Zbicz and Weight, 1985; Halliwell et al., 1986; Nakajima et al., 1986; Neumann et al., 1987; Storm, 1988). Properties held in common include activation thresholds between -60 and $-40 \mathrm{mV}$, inactivation time constants of 20-30 msec and independent of voltage, and steady state half-inactivation voltages (determined from Boltzmann relations) between -80 and $-60 \mathrm{mV}$.

$\mathrm{D}$-current characteristics in mouse hippocampal neurons differentiated them from the also present A-currents. These include steady-state inactivation curves shifted approximately $60-70$ $\mathrm{mV}$ positive, enhanced sensitivity to 4-AP (block by $100 \mu \mathrm{M}$ vs. 2-3 $\mathrm{mm}$ for A-current) and to DTx (block by $1 \mu \mathrm{M}$ ), and much slower inactivation time courses that could be fit with exponentials whose time constants varied with voltage. The first two of these properties permit separation of D-current from A-current. In hippocampal CA1 neurons in slices from adult rat, Storm (1988) also compared the properties of A- and D-currents. As for the D-currents studied here, D-current in these rat neurons activated and inactivated more slowly than A-current, and was blocked by low concentrations of $4-\Lambda \mathrm{P}$. However, in contrast to the configuration described here, D-currents in adult rat neurons activated and inactivated at voltages negative to those for A-current; half-inactivation for A-current was at -60 $\mathrm{mV}$, and for D-current it was $-88 \mathrm{mV}$. Since D-currents in other preparations of hippocampal neurons have not for the most part been investigated in the same detail, it is difficult to know if this variation is related to differences in species (mouse vs. rat), developmental stage (embryonic vs. adult), preparation (culture vs. acute slice), or recording technique (patch electrode vs. microelectrode). These last two possibilities seem less likely. 
Figure 9. 4-AP-sensitivity of steady state potassium current inactivation. $A$, Steady state inactivation determined for a day 2 cell under normal conditions and in the presence of $100 \mu \mathrm{M} 4-\mathrm{AP}$. $B$, Relative current $\left(I / I_{\max }\right)$ versus voltage for day 2 cells under normal conditions (open circles), and in the presence of $100 \mu \mathrm{M}$ 4-AP (solid circles; both are mean \pm SEM, $n=6$ ), compared to that for day 0 cells under normal conditions (solid triangles; data from Fig. 8). The curve for Day $2+4-A P$ dips below 0 because transient current was defined as $I_{\text {peak }}-I_{\text {steady state }}$, and in the presence of 4-AP, K-current activation was apparent during the test depolarizations to $+40 \mathrm{mV}$ from relatively positive conditioning depolarizations.
A
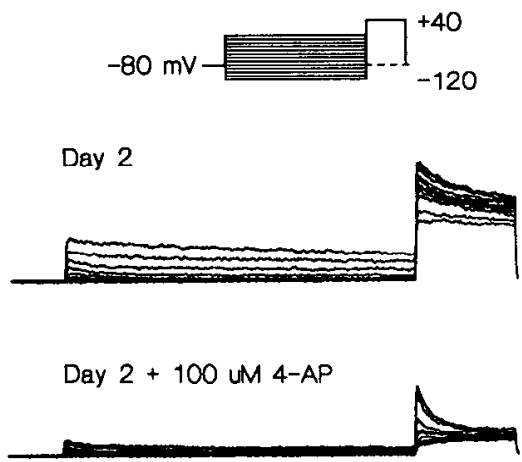

$400 \mathrm{pA}$ $100 \mathrm{msec}$

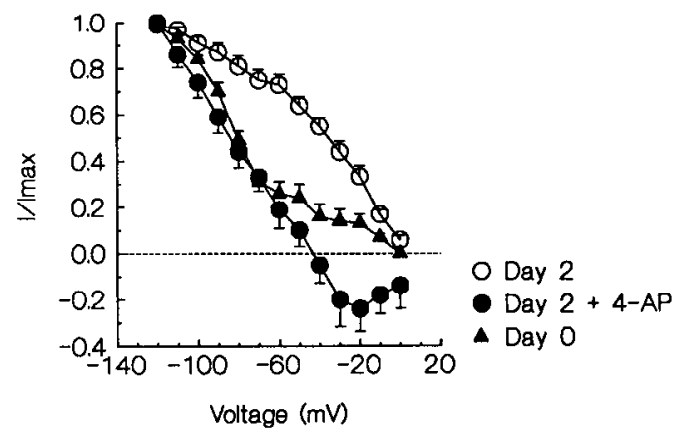

Growth in culture per se did not affect the voltage-dependent characteristics of D-current; the D-currents recorded 1-2 hr after dissociation at E15-E16 had properties identical (except for current density) to those observed after $2-3 \mathrm{~d}$ in culture. In addition, the use of patch electrodes did not appear to affect the D-currents. No large shifts in activation or inactivation parameters after rupturing the cell membrane were observed, and similar currents were recorded when $\mathrm{Cl}$ or aspartate rather than $\mathrm{F}$ were used as intracellular anions. Future experiments will address the two remaining possibilities.

D-currents in hippocampal neurons appear to be less sensitive to 4-AP and DTx than those in peripheral ncurons (see also Dolly, 1988). D-currents in DRG neurons (Stansfeld and Feltz, 1988) and nodose neurons (Stansfeld et al., 1986) are blocked by DTx at concentrations of 2-10 $\mathrm{nm}$ and by 4-AP at 20-30 $\mu \mathrm{M}$, while block in hippocampal neurons (and other central neurons) requires $350 \mathrm{nM}$ to $2 \mu \mathrm{M}$ DTx and 40-500 $\mu \mathrm{M}$ 4-AP (Gustafsson et al., 1982; Halliwell et al., 1986; Storm, 1988; Gean and Shinnick-Gallagher, 1989; Surmeier et al., 1991; present results).

\section{Contribution of $D$-currents to action potential repolarization}

Segal et al. (1984) concluded that A-current in hippocampal neurons influenced repetitive firing without affecting the waveforms of individual action potentials. An influence of D-current on action potential duration is suggested by the results presented here, and those of other studies of the action potential in hippocampal neurons (Storm, 1987, 1988), in which low concentrations of 4-AP were sufficient to delay action potential repolarization. Even a small delay in action potential repolarization could cause an increase in $\mathrm{Ca}$ entry and neurotransmitter release, as has been observed for A-current in Aplysia neurons (Shimahara, 1983). This role of D-current is consistent with the potentiating effects of D-current blockers such as DTx and MCD peptide on repetitive firing and synaptic transmission (Cherubini et al., 1987, 1988).
Figure 10. 4-AP-sensitivity of the action potential. $A$, Voltage responses to hyperpolarizing and depolarizing current injections under control conditions, and in the presence of $100 \mu \mathrm{M}$ 4-AP (day 3 cell). The peaks of the faster control action potentials may have been truncated due to sampling error. $B$, Comparison of the action potential waveforms. Shown are the first two action potentials from the most depolarized traces in $A$, with the trace recorded in the presence of 4-AP shifted horizontally to align the rising phases of the first action potentials; there was no shift along the vertical axis.
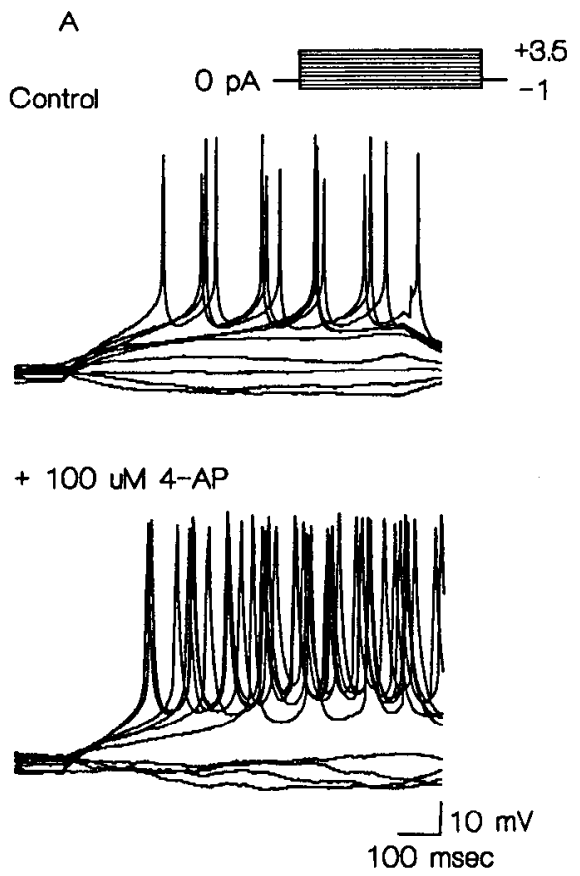


\section{Changes in $A$ - and D-current expression in culture}

Potassium currents were recorded as early as 2-3 hr after dissociation at E15-E16 (day 0 recordings). At this time A-, D-, and $\mathrm{K}$-currents were already present in the membranes of all morphologically identifiable pyramidal neurons. Transient potassium currents must thus be expressed at the time of or soon after neuronal birth, since in mice terminal differentiation of hippocampal pyramidal neurons occurs during the period E14E1 7 (Rodier, 1980). A somewhat different observation was made by Ficker and Heinemann (1989), who reported that transient potassium current was present in only approximately $50 \%$ of neurons cultured from E18 rat for 1-4 d. This variation may represent a difference between mice and rats, as we did not observe a developmental stage at which transient potassium currents were not present.

Peak and steady state current amplitudes increased during the $3 \mathrm{~d}$ from E15 to E16 that hippocampal neurons were in culture. Comparison with cell capacitance (as an index of membrane area) indicated that peak and steady state current densities increased during the period day $0-1$, but then remained stable for the next $2 \mathrm{~d}$ despite a large increase in cell capacitance between days 1 and 2 (Fig. 7). During this same interval (days 1-3) during which total outward current density remained stable, A-current density declined as D-current density increased (Figs. 7, 8). We suggest this is due to changes in current expression within a population of neurons rather than selective survival of a small (D-current-expressing) neuronal population because recordings in which D-current was dominant were never obtained from neurons studied on days 0 or 1 of culture.

This reciprocal change in A- and D-currents could be a reflection of development in culture that parallels that of neurons in situ, or it could be a consequence of removal of neurons from their glia- and trophic factor-rich environment. Arguments in favor of the first alternative are that development of glutamate receptors (NMDA- and kainate-preferring) and $\mathrm{Ca}$ channels during this same period is similar under the two growth circumstances (Barish and Mansdorf, 1991), and that D-current development trails that of A-current in rat neostriatal neurons (Surmeier et al., 1991). On the other hand, during later periods of culture (more than 5-7 d), the relative proportions of A- and D-current in the neuronal membrane are linked to proximity or contact with glial cells (R.-L. Wu and M. E. Barish, unpublished observations), an observation suggesting that neuronal isolation in culture may trigger changes in transient potassium current expression. In either event, the mechanisms responsible for changes in D-current during this $3 \mathrm{~d}$ period may also function later in development. This reciprocal plasticity of A- and D-currents, which may affect action potential repolarization and thus Ca entry, will be the subject of future investigations.

\section{References}

Ahmed Z (1988) Expression of membrane currents in rat neocortical neurons in serum-free culture. II. Outward currents. Dev Brain Res 40:297-305.

BankerGA, Cowan WM (1977) Rat hippocampal neurons in dispersed cell culture. Brain Res 126:397-425.

Barish ME, Mansdorf NB (1991) Development of intracellular calcium responses to depolarization and to kainate and $N$-methyl-D-aspartate in cultured mouse hippocampal neurons. Dev Brain Res 63:53-61.

Barish ME, Mansdorf NB, Raissdana SS (1991) $\gamma$-Interferon promotes differentiation of cultured cortical and hippocampal neurons. Dev Biol 144:4.12-423.
Castle NA, Haylett DG, Jenkinson DH (1989) Toxins in the characterization of potassium channels. Trends Neurosci 12:59-65.

Cherubini E, Ben Ari Y, Gho M, Bidard JN, Lazdunski M (1987) I ong-term potentiation of synaptic transmission in the hippocampus induced by a bee venom peptide. Nature 328:70-73.

Cherubini E, Neuman R, Rovira C, Ben Ari Y (1988) Epileptogenic properties of the mast cell degranulating peptide in $\mathrm{CA} 3$ hippocampal neurones. Brain Res 445:91-100.

Connor JA, Stevens CF (1971a) Voltage clamp studies of a transient outward membrane current in gastropod neural somata. J Physiol (Lond) 213:21-30.

Connor JA, Stevens CF (1971b) Prediction of repetitive firing behaviour from voltage clamp data on an isolated neurone soma. J Physiol (Lond) 213:31-53.

Cull-Candy SG, Marshall CG, Ogden D (1989) Voltage-activated membrane currents in rat cerebellar granule neurones. J Physiol (Lond) 414:179-199.

Dolly JO (1988) Potassium channels - what can the protein chemistry contribute? Trends Neurosci 11:186-188.

Ficker E, Heinemann U (1989) $\mathrm{K}^{+}$currents in developing hippocampal cells. Pfluegers $\Lambda$ rch 414 [Suppl 1]:S125.

Gean PW, Schinnick-Gallagher P (1989) The transient potassium current, the A current, is involved in spike frequency adaptation in rat amygdala neurons. Brain Res 480:160-169.

Greene RW, Haas HL, Reiner PB (1990) Two transient outward currents in histamine neurones of the rat hypothalamus. J Physiol (Lond) 420:149-163.

Gustafsson B, Galvan M, Grafe P, Wigström H (1982) A transient outward current in a mammalian central neurone blocked by 4-aminopyridine. Nature 299:252-254.

Hagiwara S, Kusano K, Saito N (1961) Membrane changes of Onchidium nerve cell in potassium-rich media. J Physiol (Lond) 155:470489 .

Halliwell JV, Othman IB, Pelchen-Matthews A, Dolly JO (1986) Central action of dendrotoxin: selective reduction of a transient $\mathrm{K}$ conductance in hippocampus and binding to localized acceptors. Proc Natl Acad Sci USA 83:493-497.

Hamill OP, Marty A, Neher E, Sakmann B, Sigworth F (1981) Improved patch-clamp techniques for high-resolution current recordings from cells and cell-free membrane patches. Pfluegers Arch 391:85100.

Kay AR, Miles R, Wong RKS (1986) Intracellular fluoride alters the kinetic properties of calcium currents facilitating the investigation of synaptic events in hippocampal neurons. J Neurosci 6:2915-2920.

Kostyuk PG, Krishtal OA, Shakhovlov YA (1977) Separation of sodium and calcium currents in the somatic membrane of mollusc neurones. J Physiol (Lond) 270:545-568.

Kriegstein AR, Dichter MA (1983) Morphological classification of rat cortical ncurons in cell culture. J Neurosci 3:1634-1647.

Laurent G (1991) Evidence for voltage-activated outward currents in the neuropilar membrane of locust nonspiking local interneurons. J Neurosci 11:1713-1726.

Mirolli M (1981) Fast inward and outward current channels in a nonspiking neurone. Nature 292:251-253.

Moczydlowski E, Lucchesi K, Ravindran A (1988) An emerging pharmacology of peptide toxins targeted against potassium channels. J Membr Biol 105:95-111.

Nakajima Y, Nakajima S, Leonard RJ, Yamaguchi K (1986) Acetylcholine raises excitability by inhibiting the fast transient potassium current in cultured hippocampal neurons. Proc Natl Acad Sci USA 83:3022-3026.

Neher E (1971) Two fast transient current components during voltage clamp on snail ncurons. J Gen Physiol 58:36-53.

Neumann RE, Wadman WJ, Wong RKS (1987) Outward currents of single hippocampal cells obtained from the adult guinea-pig. J Physiol (Lond) 393:331-353.

Rodier PM (1980) Chronology of neuron development: animal studies and their clinical implications. Dev Med Child Neurol 22:525-545.

Rogawski MA (1985) The A-current: how ubiquitous a feature of excitable cells is it? Trends Neurosci 8:214-219.

Rudy B (1988) Diversity and ubiquity of K channels. Neuroscience 25:729-749.

Segal M, Barker JL (1984) Rat hippocampal neurons in culture: potassium conductances. J Neurophysiol 51:1409-1433.

Segal M, Rogawski MA, Barker JL (1984) A transient potassium con- 
ductance regulates the excitability of cultured hippocampal and spinal neurons. J Neurosci 4:604-609.

Serrano EE, Getting PA (1989) Diversity of the transient outward potassium current in somata of identified molluscan neurons. J Neurosci 9:4021-4032.

Shimahara T (1983) Presynaptic modulation of transmitter release by the early outward potassium current in Aplysia. Brain Res 263:5156.

Spain WJ, Schwindt PC, Crill WE (1991) Two transient potassium currents in layer $\mathrm{V}$ pyramidal neurones from cat sensorimotor cortex. J Physiol (Lond) 434:591-607.

Stansfeld CE, Feltz A (1988) Dendrotoxin-sensitive $\mathrm{K}^{+}$channels in dorsal root ganglion cells. Neurosci Lett 93:49-55.

Stansfeld CE, Marsh SJ, Halliwell JV, Brown DA (1986) 4-Aminopyridine and dendrotoxin induce repetitive firing in ral visceral sensory neurons by blocking a slowly inactivating outward current. Neurosci Lett 64:299-304.

Stansfeld CE, Marsh SJ, Parcej DN, Dolly JO, Brown DA (1987) Mast cell degranulating peptide and dendrotoxin selectively inhibit a fastactivating potassium current and bind to common neuronal proteins. Neuroscience 23:893-902.

Stansfeld CE, Fagni L, Marsh SJ, Brown DA, Feltz A (1991) Kinetics of the dendrotoxin-sensitive $\mathrm{K}$ current in dissociated dorsal root ganglion (DRG) neurones of the rat. J Physiol (Lond) 234:91p.

Storm JF (1987) Action potential repolarization and a fast after-hy- perpolarization in rat hippocampal pyramidal cells. J Physiol (Lond) 385:733-759.

Storm JF (1988) Temporal integration by a slowly inactivating $\mathrm{K}^{+}$ current in hippocampal neurons. Nature 336:379-381.

Storm JF (1990) Potassium currents in hippocampal pyramidal cells. Prog Brain Res 83:161-187.

Surmeier DJ, Bargas J, Kitai ST (1989) Two types of A-current differing in voltage-dependence are expressed by neurons of the rat neostriatum. Neurosci Lett 103:331-337.

Surmeier DJ, Stefani A, Foehring RC, Kitai ST (1991) Developmental regulation of a slowly-inactivating potassium conductance in rat neostriatal neurons. Neurosci Lett 122:41-46.

Takahashi T (1990) Membrane currents in visually identified motoneurones of neonatal rat spinal cord. J Physiol (Lond) 423:27-46.

Thompson SH (1977) Three pharmacologically distinct potassium channels in molluscan neurones. J Physiol (Lond) 265:465-488.

Wu R-L, Barish ME (1991) Development of two transient potassium currents in cultured mouse hippocampal neurons. Soc Neurosci Abstr 17:1098.

Zbicz KL, Weight FF (1985) Transient voltage and calcium-dependent outward currents in hippocampal CA3 pyramidal neurons. J Neurophysiol 53:1038-1058.

Zona C, Pirrone G, Avoli M, Dichter M (1988) Delayed and fast transient potassium currents in rat neocortical neurons in cell culture. Neurosci Lett 94:285-290. 